\title{
Reducing Moringa Leaflet Abscission after Irradiation and during Shipping
}

\author{
Robert E. Paull ${ }^{1}$ and Gail Uruu ${ }^{1}$
}

AdDitional INDEX wORDs. 1-MCP, chilling injury, herbs, Moringa oleifera, quality

Summary. Moringa (Moringa oleifera), also known as the pot herb drumstick or horseradish leaves, requires irradiation treatment for insect disinfestation before shipping to the west coast of the United States from Hawai'i. This irradiation treatment as well as packing and air shipment leads to leaflet abscission. To minimize this abscission, the shipper had been including frozen gel packs in the shipping carton. However, these packs are heavy and lead to chilling injury on the leaflets and the development of mold on the leaves adjacent to the gel pack. Holding and shipping the product at $12^{\circ} \mathrm{C}$ negated the need for the frozen gel packs. Inclusion of a sachet of 1-methylcyclopropene in the carton significantly reduced leaflet abscission. Further reduction was obtained by the inclusion of an ethylene absorption sachet, thus helping to maintain the overall product quality and marketability.

M oringa (Moringa oleifera), also called drumstick tree and horseradish tree, is a fast-growing tree that is grown throughout the tropics for human food, as an herb, for medicine, as livestock forage, as a dye, and for water purification. Almost every part of this tree has value as food (Gupta et al., 1989). Moringa produces long pods that have the taste of asparagus and a mass of very small leaflets. The young plants less than $50 \mathrm{~cm}$ tall are eaten as a tender vegetable. The small leaflets are eaten as greens in salads, in vegetable curries, as pickles, and for seasoning and can be sun dried and stored for future use. The flowers can be eaten or used to make a tea. Leaves and branches can be fed to livestock as fodder. Moringa is widely used as a pot herb in the Philippines known as malunggay (Foidl et al., 2001; Jahn, 1989; Radovich, 2009) and is shipped from Hawai'i to the west

Received for publication 17 Sept. 2020. Accepted for publication 1 Dec. 2020

Published online 7 January 2021

${ }^{1}$ Tropical Plant and Soil Sciences, University of Hawai'i at Manoa, Honolulu, HI 96822

The project was supported in part by the U.S. Department of Agriculture, National Institute of Food and Agriculture, Hatch Project H862 to Robert E. Paull. We acknowledge Michael Kohn of Pa'ina Hawai'i LLC, Hawai'i for irradiating the product and helping with the sourcing of Moringa leaves, and Samson Delos Reyes of SJ Vegetable Farms, Wai'anae, Hawai'i for supplying the leaves.

R.E.P. is the corresponding author. E-mail: paull@ hawaii.edu.

This is an open access article distributed under the CC BY-NC-ND license (https://creativecommons.org/ licenses/by-nc-nd/4.0/).

https://doi.org/10.21273/HORTTECH04738-20 coast of the United States, especially California, for this purpose.

To ship the leaves from Hawai'i to the mainland of the United States, they must be treated to control insects (Follett and Weinert, 2012; Roberts and Follett, 2017). The most common treatment is gamma irradiation with a minimum dose of $400 \mathrm{~Gy}$ for all insects other than tephritid fruit flies [Tephritidae (Follett, 2009)]. However, moringa leaves, when shipped from Honolulu after irradiation, often show leaflet abscission from the rachis. Other conditions include leaflet blackening, which especially occurs on leaves next to the ice pack, if used, during shipping. Mold is sometimes seen among the leaves near the ice pack after it has thawed. This research was undertaken to determine if treatment with 1-methylcyclopropene (1MCP) can minimize leaflet abscission and avoid the use of cold packs in the shipping carton.

\section{Materials and methods}

The moringa leaves were obtained from an Oahu farmer on the drier Wai'anae coast who ships moringa leaves weekly to California after irradiation. The farmer harvested and packed the leaves that were chilled overnight at $\approx 45^{\circ} \mathrm{F}$ into the normal shipping carton $(10 \mathrm{lb})$ in a cold room before delivery to the irradiation plant the next morning. At the irradiation plant, the leaves were sorted into three replications per treatment and packed into smaller cartons $[11 \times 8.5 \times 5.5$ inches inside $\left.\left(0.3 \mathrm{ft}^{3}\right)\right]$ lined with a polyethylene bag (1-mil-thick) that was folded over the product; then, the carton taped shut. Taping the carton closed is required as part of the disinfestation protocol. Frozen gel ice packs $(1 \mathrm{lb})$ wrapped in four to five sheets of newsprint, as used with the current shipping protocol, were placed in the bottom of some cartons depending on treatment. The treatment cartons were then treated at $\approx 475$ Gy and held at $7{ }^{\circ} \mathrm{C}$ for $2 \mathrm{~d}$, followed by another $4 \mathrm{~d}$ at $12{ }^{\circ} \mathrm{C}$. This protocol simulated the current handling practices of 6 to $7 \mathrm{~d}$ for shipping product from Hawai'i to California. To reflect the limitations in the supply chain to control temperature variation in airshipped products, cartons were also stored at either 12 or $22{ }^{\circ} \mathrm{C}$ for 6 $\mathrm{d}$ after irradiation. Treatments were performed on multiple days over several months and followed the same protocol unless otherwise stated.

Sachets of 1-MCP as an inclusion complex in alpha-cyclodextrin were made using a nonwoven, high-density, spun-bound polyethylene material (Tyvek; DuPont, Wilmington, DE) and heat-sealed, with each sachet containing $0.07 \mathrm{mg}$ l-MCP (Smart Fresh; AgroFresh Solutions, Collegeville, PA). These sachets and two 10 -g ethylene-absorbent zeolite sachets (Dry Pak Industries, Encino, CA), were enclosed with the product in the plastic bags inside the carton, as required.

On completion of storage, rachi were sorted individually into "marketable" $(\geq 70 \%$ of the leaves on the rachi

\begin{tabular}{llll}
\hline $\begin{array}{l}\text { Units } \\
\text { To convert U.S. to SI, } \\
\text { multiply by }\end{array}$ & U.S. unit & SI unit & $\begin{array}{l}\text { To convert SI to U.S., } \\
\text { multiply by }\end{array}$ \\
\hline 0.0283 & $\mathrm{ft}^{3}$ & $\mathrm{~m}^{3}$ & 35.3147 \\
2.54 & inch $(\mathrm{es})$ & $\mathrm{cm}$ & 0.3937 \\
0.4536 & $\mathrm{lb}$ & $\mathrm{kg}$ & 2.2046 \\
28.3495 & $\mathrm{oz}$ & $\mathrm{g}$ & 0.0353 \\
28,350 & $\mathrm{OZ}$ & $\mathrm{mg}$ & $3.5274 \times 10^{-5}$ \\
$\left({ }^{\circ} \mathrm{F}-32\right) \div 1.8$ & ${ }^{\circ} \mathrm{F}$ & ${ }^{\circ} \mathrm{C}$ & $\left({ }^{\circ} \mathrm{C} \times 1.8\right)+32$
\end{tabular}


present and of edible quality) and "unmarketable" (<70\% edible leaves). Quality was also subjectively evaluated for overall appearance for the replication as a whole. The degrees of darkening, dehydration, and decay on the leaf surface and stem were visually evaluated according to a five-level scale (Aharoni et al., 2010), where $1=$ all leaves are symptomfree; 2 = slight injury with mild discoloration and/or necrosis on the leaves and $\approx 5 \%$ of the leaves showing damage; $3=$ approximately one-fifth of the leaves showing damage; $4=$ most of the leaves showing damage; and $5=$ all of the leaves showing damage. The produce was considered to be of commercial quality up to an index value of 2.5; scores above this level meant that the produce was unmarketable. The rate of abscission was evaluated by weighing the abscised leaves relative to the total leaf fresh weight.

During preliminary tests, the nonirradiated treatment showed $14 \% \pm$ $14 \%$ leaflet abscission and the

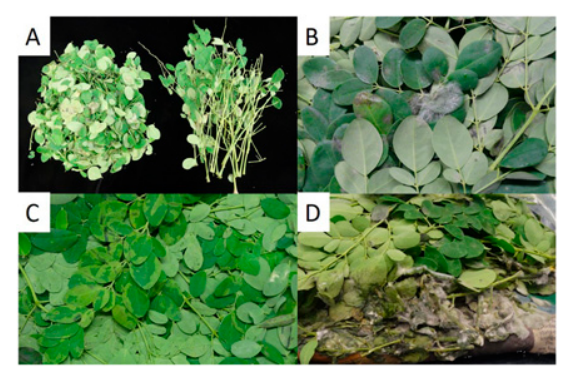

Fig. 1. Disorders of moringa leaves observed during shipping: (A) extreme abscission of leaflets following irradiation and storage; (B) mold growth on leaves following the holding of a packed carton at room temperature $\left[22{ }^{\circ} \mathrm{C}\left(71.6^{\circ} \mathrm{F}\right)\right]$ for $\mathrm{I}$ week; (C) chilling injury symptoms on leaflets caused by water-soaking; and (D) mold growth adjacent to the ice gel pack wrapped in newspaper after thawing and possible freezing damage immediately next to the ice pack.

Table 1. Effects of gel ice and $0.07 \mathrm{mg}\left(2.469 \times 10^{-6} \mathrm{oz}\right) 1$-methylcyclopropene (1-MCP) on irradiated moringa leaves after storage for $2 \mathrm{~d}$ at $7^{\circ} \mathrm{C}\left(44.6^{\circ} \mathrm{F}\right)$ and $4 \mathrm{~d}$ at $12{ }^{\circ} \mathrm{C}\left(53.6^{\circ} \mathrm{F}\right)$ on leaflet abscission and product marketability.

\begin{tabular}{lcc}
\hline Treatment & Abscised leaflets (\%) & Unmarketable product (\%) \\
\hline Irradiated & $40 \mathrm{ab}^{\mathrm{z}}$ & $57 \mathrm{ab}$ \\
Irradiated + gel ice & $74 \mathrm{a}$ & $93 \mathrm{a}$ \\
Irradiated + l-MCP & $28 \mathrm{ab}$ & $50 \mathrm{ab}$ \\
Irradiated + gel ice + 1-MCP & $19 \mathrm{~b}$ & $30 \mathrm{~b}$ \\
\hline
\end{tabular}

${ }^{\mathrm{z}}$ Mean separation by the Duncan-Waller multiple range test at $P=0.05$. Means with the same letter after the mean were not significantly different.

irradiated treatment had $69 \% \pm 13 \%$ abscission (data not reported). During subsequent tests, irradiation alone served as the control. The irradiated control and all treatments were performed with three replications. All reported experiments were duplicated. Data were analyzed with statistical software (SAS version 9.1; SAS Institute, Cary, NC) using the GLM Procedure.

\section{Results and discussion}

The immediate observations of commercial cartons subject to simulated shipping were a significant amount of leaflet abscission (Fig. 1A) and condensation found in some of the cartons. Condensation was particularly noticed in cartons that had gel ice packs. Leaflet chilling injury was indicated by water-soaked areas on the leaflets (Fig. IB and C). Mechanical damage and leaflet blackening were also noticed. Condensation inside the bag and on the leaves could be conducive to mold growth (Fig. 1D). Layering a polystyrene foam sheet over the gel ice pack prevented direct contact and reduced damage to the leaves.

Irradiation of moringa leaves induced leaflet shedding (Fig. 1A). The leaflet abscission rate increased from $\approx 1 \%$ for the nonirradiated control to $\approx 16 \%$ with irradiation when leaves were packed without ice and $23 \%$ when an ice pack was included in the carton. However, variations were noticed between batches of leaves from different harvests, with the nonirradiated control varying from $1 \%$ to up to $13 \%$ and the irradiated product varying from $3 \%$ to $79 \%$.

The addition of a sachet of 1 MCP in the carton with a gel ice pack with irradiation significantly reduced the rate of abscission and improved the overall quality of irradiated product following storage at $7{ }^{\circ} \mathrm{C}$ for 2

Hortlechnology · February $202131(1)$ $\mathrm{d}$ and $12{ }^{\circ} \mathrm{C}$ for $4 \mathrm{~d}$ (Table 1 ). During preliminary tests, it was found that the addition of a 1-MCP sachet reduced leaflet abscission from an average of $57 \%$ to $22 \%$.

The presence of a gel ice pack in the carton did not significantly reduce the leaflet abscission or unmarketable product percentage of irradiated leaves with a 1-MCP sachet present when held for $6 \mathrm{~d}$ at an ambient temperature of $22{ }^{\circ} \mathrm{C}$ (abscission: $63 \%$ vs. $76 \%$ ). A gel ice pack significantly reduced leaflet abscission (from $\approx 32 \%$ to $\approx 14 \%$ ) and marketable product (from $56 \%$ to $30 \%$ ) when included with irradiation in the presence of a 1-MCP sachet in cartons held for $6 \mathrm{~d}$ at $12^{\circ} \mathrm{C}$ (Table 2 ). Lowtemperature storage at $5^{\circ} \mathrm{C}$ has been reported to increase the postharvest life of moringa leaves that were not subject to irradiation (Suganthi et al., 2019).

The response to $1-\mathrm{MCP}$ suggested that ethylene is involved in leaflet abscission. Harvesting and postharvest handling can lead to mechanical injury and stress ethylene production; therefore, the inclusion of an ethylene-absorbent sachet was evaluated. When an ethylene-absorbent sachet was alone in the carton, it did not significantly reduce abscission and did not suggest commercial utility (Table 3 ). The 1-MCP sachet reduced leaflet abscission from $64 \%$ to $26 \%$ for the irradiated control $(P=$ $0.089)$. There was also improvement in both leaf abscission (from $64 \%$ to $3 \%$ ) and overall quality (from 90\% unmarketable to $30 \%$ unmarketable) when a combination of 1-MCP packets and ethylene-absorbent sachets was tested (Table 3 ).

Overall, 1-MCP was a useful treatment that reduced leaflet abscission and maintained product quality. Gel ice and 1-MCP reduced leaflet abscission when used together. Gel ice and 1-MCP combined resulted in a product with better quality and less mold if the gel ice was properly insulated to prevent chilling injury. Mold was frequently seen near the thawed gel ice, where considerable condensation occurred (Fig. 1). Therefore, the gel ice might not be needed if a 1-MCP sachet is included in the carton, especially if the cartons are kept cool during shipping. A combination of 1-MCP and an ethylene-absorbent sachet in the carton 
Table 2. Effects of the use of gel ice packs and different storage temperatures on moringa leaflet abscission and marketability $(\mathrm{n}=3)$ after being held with $0.07 \mathrm{mg}\left(2.469 \times 10^{-6} \mathrm{oz}\right) 1$-methylcyclopropene (1-MCP) at $12^{\circ} \mathrm{C}$ or $22^{\circ} \mathrm{C}\left(53.6\right.$ or $\left.71.6^{\circ} \mathrm{F}\right)$ for $6 \mathrm{~d}$ with or without gel ice.

\begin{tabular}{lcr}
\hline Treatment & Abscised leaflets (\%) & Unmarketable product (\%) \\
\hline Irradiated + 1-MCP 12 ${ }^{\circ} \mathrm{C}$ & $32 \mathrm{~b}^{\mathrm{z}}$ & $56 \mathrm{~b}$ \\
Irradiated + 1-MCP $22{ }^{\circ} \mathrm{C}$ & $76 \mathrm{a}$ & $100 \mathrm{a}$ \\
Irradiated $+1-\mathrm{MCP}+$ gel ice $12{ }^{\circ} \mathrm{C}$ & $14 \mathrm{c}$ & $30 \mathrm{c}$ \\
Irradiated $+1-\mathrm{MCP}+$ gel ice $22{ }^{\circ} \mathrm{C}$ & $63 \mathrm{a}$ & $100 \mathrm{a}$ \\
\hline
\end{tabular}

${ }^{\mathrm{z}}$ Mean separation by the Duncan-Waller multiple range test at $P=0.05$. Means with the same letter after the mean were not significantly different.

Table 3. Effects of $0.07 \mathrm{mg}\left(2.469 \times 10^{-6} \mathrm{oz}\right) 1$-methylcyclopropene (1-MCP) and $10 \mathrm{~g}(0.35$ oz $)$ ethylene $\left(\mathrm{C}_{2} \mathrm{H}_{4}\right)$ absorbent after $2 \mathrm{~d}$ at $7^{\circ} \mathrm{C}\left(44.6^{\circ} \mathrm{F}\right)$ and $4 \mathrm{~d}$ at $12^{\circ} \mathrm{C}\left(53.6^{\circ} \mathrm{F}\right)$ on leaflet abscission and product marketability.

\begin{tabular}{lcc}
\hline Treatment & Abscised leaflets (\%) & Unmarketable product (\%) \\
\hline Irradiated & $64 \mathrm{a}^{\mathrm{z}}$ & $90 \mathrm{a}$ \\
Irradiated $+1-\mathrm{MCP}$ & $26 \mathrm{ab}$ & $40 \mathrm{~b}$ \\
Irradiated $+\mathrm{C}_{2} \mathrm{H}_{4}$ absorbent & $63 \mathrm{a}$ & $78 \mathrm{a}$ \\
Irradiated $+1-\mathrm{MCP}+\mathrm{C}_{2} \mathrm{H}_{4}$ absorbent & $3 \mathrm{~b}$ & $30 \mathrm{~b}$ \\
\hline
\end{tabular}

${ }^{\mathrm{z}}$ Mean separation by the Duncan-Waller multiple range test at $P=0.05$. Means with the same letter after the mean were not significantly different.

also improved product quality. The 1MCP satchels used in this test were made in the laboratory. Equivalent sachets for in-transit use with fresh fruit, vegetables, and herbs are approved in many countries; however, at this time they are approved for only kiwifruit (Actinidia deliciosa) in California.

An alternative marketing strategy would be to add value on-farm by shipping only abscised leaflets. The leaflets could be packaged in a small, clear polystyrene clamshell. However, discussions have suggested that shipping whole leaves is an "indication" of freshness, and that abscised leaflets are regarded as old.

\section{Literature cited}

Aharoni, N., D. Kenigsbuch, D. Chalupowicz, M. Faura-Mlinski, Z. Aharon, D. Maurer, A. Ovadia, and A. Lers. 2010. Reducing chilling injury and decay in stored sweet basil. Isr. J. Plant Sci. 58:167-181, doi: 10.1560/ IJPS.58.3-4.167.
Foidl, N., H.P.S. Makkar, and B.K.N. Foidl. 2001. The potential of Moringa oleifera for agricultural and industrial uses, p. 45-76. In: L.J. Fuglie (ed.). L'arbre de la Vie, Les multiples usages du moringa. Centres de traitement ambulatoire du SIDA (CTA) and Eau et assainissement à base communautaire (CWS), Dakar, Senegal.

Follett, P.A. 2009. Generic radiation quarantine treatments: The next steps. J. Econ. Entomol. 102:1399-1406, doi: 10.1603/029.102.0401.

Follett, P.A. and E.D. Weinert. 2012. Phytosanitary irradiation of fresh tropical commodities in Hawaii: Generic treatments, commercial adoption, and current issues. Radiat. Phys. Chem. 8:1064-1067, doi: 10.1016/j.radphyschem.2011.12.007.

Gupta, M., G.K. Barat, D.S. Wagle, and H.K. Chawla. 1989. Nutrient contents and antinutritional factors in conventional and non-conventional leafy vegetables. Food Chem. 31:105-116, doi: 10.1016/ 0308-8146(89)90021-6.
Jahn, S.A.A. 1989. Moringa oleifera for food and water purification - Selection of clones and growing annual short stem. Entwicklung und Landlicher Raum 4:2225.

Radovich, T. 2009. Farm and forestry production and marketing profile for moringa (Moringa oleifera), p. 329-340. In: C.R. Elevitch (ed.). Specialty crops for Pacific Islands. 8 June 2020. <https://www. agroforestry.org/free-publications/specialtycrops-for-pacific-island-agroforestry>.

Roberts, P.B. and P.A. Follett. 2017. Food irradiation for phytosanitary and quarantine treatment, p. 169-182. In: I.C.F.R. Ferreira, A.L. Antonio, and S.C. Verde (eds.). Food irradiation technologies: Concepts, applications and outcomes. Royal Soc. Chem., London, UK. doi: 10.1039/9781788010252-00169.

Suganthi, M., T.N. Balamohan, A. Beaulah, and S. Vellaikumar. 2019. Extending the shelf life of moringa leaves through packaging and cold storage. Intl. J. Chem. Stud. 7:483-486. 